\title{
Use of Finite Difference Numerical Technique to Evaluate Deep Patch Embankment Repair with Geosynthetics
}

\section{Authors: Steve Perkins, Eli Cuelho, Michelle Akin, \& Brian Collins}

This is a postprint of an article that originally appeared in Transportation Research Record on March 2015.

Perkins, Steve, Eli Cuelho, Michelle Akin, and Brian Collins. "Use of Finite Difference Numerical Technique to Evaluate Deep Patch Embankment Repair with Geosynthetics." Transportation Research Record, no. 2473 (March 2015): 217-223. DOI: $10.3141 / 2473-25$.

Made available through Montana State University's ScholarWorks scholarworks. montana.edu 


\section{USE OF FINITE DIFFERENCE NUMERICAL TECHNIQUE TO EVALUATE DEEP PATCH EMBANKMENT REPAIR WITH GEOSYNTHETICS}

Steve Perkins (corresponding author)

Professor

Montana State University

205 Cobleigh Hall

Bozeman, MT 59715

406-994-6119 (office)

406-994-6105 (fax)

stevep@ce.montana.edu

Eli Cuelho

Research Engineer

Western Transportation Institute

P.O. Box 174250

Bozeman, MT 59717-4250

406-994-7886

406-994-1697

elic@coe.montana.edu

Michelle Akin

Research Associate

Western Transportation Institute

P.O. Box 174250

Bozeman, MT 59717-4250

406-994-6356

406-994-1697

michelle.akin@coe.montana.edu

Brian Collins

Geotechnical Engineer

Western Federal Lands Highway Division

610 East Fifth Street

Vancouver, WA 98661-3801

360-619-7657 (office)

306-619-7845 (fax)

brian.collins@dot.gov

Submission date: March 28, 2014

Number of words in Text $=3885$

Number of Figures $=12$

Number of Tables $=2$ 


\begin{abstract}
Low-volume roads constructed in steep hillside terrain by cut and cast techniques may experience instability in the form of excessive subsidence leading to large cracks and differential movement along the roadway bench. The deep patch embankment repair with geosynthetics (DPERG) technique has been employed in the Western United States and generally involves a 1 to $2 \mathrm{~m}$ deep excavation that is backfilled with compacted granular soils and one or more layers of geosynthetic reinforcement. The design goal of a DPERG, is not necessarily to eliminate future slope movement but to confine potential failure surfaces to a region of the slope well below the roadway bench and extending out to the slope face such that a failure surface does not extend up onto the roadway bench. This results in movement along the roadway bench that is more uniform and less disruptive to traffic. This paper describes the results of a study to evaluate the DPERG technique by analytical methods supported by field observations for the purpose of determining the required depth of the DPERG and the optimum layer spacing of the reinforcement. The study shows that for a given slope geometry and set of soil properties that has led to failure in an unreinforced slope, there are several combinations of depth of the DPERG and number of reinforcement layers that result in satisfying the design goal. The study shows that more tightly spaced reinforcement layers are beneficial and that for widely spaced layers, the design goal of a DPERG cannot be met even for a thick depth of the DPERG.
\end{abstract}

\title{
INTRODUCTION
}

Low-volume roads in steep hillside terrain are commonly constructed by cutting into the uphill side of the road and casting material onto the downhill side. Due to the steepness of the hillside, the side cast soils are generally placed with minimal or no compaction effort. In addition, vegetation may not have been adequately removed prior to placement of side cast fill soils. These conditions may lead to excessive settlement, creep and instability within the side cast fill soil or along the contact surface between the fill soil and the native ground, which in turn may lead to roadway surface distresses such as large cracks, subsidence and differential movement.

In the Western United States, a deep patch embankment repair with geosynthetics technique (DPERG) has been used to address roadways experiencing these types of distresses. The technique, also referred to as a deep patch, has historically involved a 1 to $2 \mathrm{~m}$ deep excavation along the length of the roadway experiencing the distress, which is then backfilled with compacted granular materials and several layers of geosynthetic reinforcement. The design philosophy for a DPERG is to force potential failure surfaces to the face of the weak soil slope and to confine them to regions well below the roadway bench. This prevents failure surfaces from extending up into the roadway bench. In the event of failure, the reinforced roadway bench may experience vertical movement, however the movement is more uniform and thereby avoids larger problems such as severe cracking, differential movement, reduced traffic safety and increased disruption to traffic. This implies that a satisfactory factor of safety exists for potential failure surfaces extending up into the roadway bench while an inadequate factor of safety may exist for regions of the slope well below the bench and extending to the slope face.

Despite the fact that the deep patch technique has been used for over 20 years (1), there has been insufficient information documented about their performance, design and construction. Wu and Helwany (2) carried out a large laboratory scale model study of an idealized deep patch configuration involving a reinforced embankment with a section of the bottom that could be lowered to simulate movement of an underlying fill. The principal goal of the study was to evaluate the significance of the reinforcement as compared to well-compacted backfill without 
any reinforcement. The study showed that the reinforcement interacted with the surrounding backfill to produce a stiffened composite that provided a significant cantilever effect, which greatly reduced the potential for shearing and crack development along the roadway bench.

Ohta et al. (3) described the construction of a trial embankment with a height of $5 \mathrm{~m}$ constructed with an overhanging face (Figure 1). Ten equally spaced layers of a geogrid having an ultimate strength of $111 \mathrm{kN} / \mathrm{m}$ were used. The support embankment (shown on the left side of the reinforced mass) was in place during construction and then completely removed. This resulted in approximately $200 \mathrm{~mm}$ of vertical settlement of the top of the reinforced embankment and no gross failure. A second embankment was constructed with a weaker geogrid having an ultimate strength of $35.6 \mathrm{kN} / \mathrm{m}$ and failed once the support fill was removed. Together with the study by $\mathrm{Wu}$ and Helwany (2), these results show the ability of a geosynthetic reinforced mass to resist failure when configured as a cantilever. The overhanging embankment is analyzed in this study as a means of validating the model's ability to account for cantilever action.

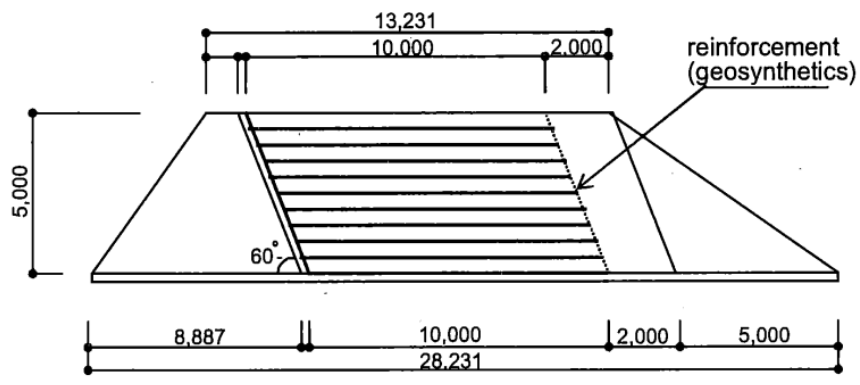

Figure 1: Configuration of overhanging embankment (Ohta et al. (3)). All dimensions in mm.

Vulova and Leshchinsky (4) performed a numerical study of MSE walls that illustrated the importance of reinforcement spacing, which is also important for the performance of a deep patch. The numerical investigation determined the critical wall height for various combinations of different soil types, reinforcement spacing geometries, and reinforcement stiffness. The critical wall height was the maximum wall height associated with a stable configuration. Smaller reinforcement spacing $(0.2$ to $0.4 \mathrm{~m})$ compared to 0.6 to $1 \mathrm{~m}$ generated greater internal stability causing the reinforced soil to move as a coherent mass. All other parameters being equal, smaller spacing was associated with greater critical wall heights. Smaller spacing could also make up for lower strength soil by allowing a similar critical wall height. Thus, reinforcement spacing was identified as a major factor controlling all aspects of wall behavior.

This paper describes the results of a study to evaluate the DPERG technique by analytical methods supported by field observations for the purpose of determining the required depth of the deep patch and the optimum layer spacing of the reinforcement.

\section{NUMERICAL MODEL AND VALIDATION}

The finite difference numerical program FLAC/Slope ${ }^{\mathrm{TM}}$ (Itasca $^{\mathrm{TM}}$ ) was used to model embankments. The model is a two-dimensional program using a Mohr-Coulomb plasticity model for the soil materials. The numerical model operates by a shear strength parameter reduction technique where the shear strength parameters (cohesion and friction angle) of the soil units are incrementally reduced until failure occurs. Failure is defined as non-convergence of the solution, which implies that global equilibrium cannot be reached while satisfying the failure criterion of the soil. This in turn implies that the slope mass is sliding excessively along the failure surface 
such that equilibrium cannot be restored. Geosynthetic reinforcement is modeled by specifying an elastic modulus and an ultimate yield strength. The interface between the soil and the geosynthetic is characterized by a friction angle and a bond strength.

To show the ability of the model to describe a reinforced mass' ability to resist cantilever effects, the configuration shown in Figure 1 was modeled. Data provided by Ohta et al. (3) indicated that the sand used in the embankment had a friction angle of $42^{\circ}$ and a cohesion of 25 $\mathrm{kPa}$. The geogrid had an ultimate tensile strength of $111 \mathrm{kN} / \mathrm{m}$ and an elastic modulus of 3700 $\mathrm{MPa}$. Using these properties, the numerical model produced a factor of safety against failure of 1.5. In addition, the pattern of failure appeared to match that shown by Ohta et al. (3) for the slope with the weaker reinforcement. The pattern of failure for this slope corresponded to vertical movement of a triangular wedge of soil along with rupture of the geogrid along a vertical line extending upwards from the toe of the slope.

\section{EMBANKMENT CONFIGURATION}

Figure 2 provides a diagram of a typical cross-section of a low volume roadway constructed on a steep hillside by cutting into the uphill side of the roadway and casting material onto the downhill hillside. For purposes of this study, this cross-section has been generalized by the geometry and slope configuration parameters shown in Figure 2. In Figure 2, $\alpha$ is the angle of the original slope and $\beta$ is the angle of the slope after the side cast fill operation is completed. The slope height, $H$, defines the vertical height from the toe of the side cast slope to the roadway bench. The geometric parameter $X$ is a horizontal distance along the roadway bench defining the upper portion of the side cast fill zone. For a roadway that has experienced distress due to movement of the side cast fill, the horizontal distance $X_{c}$ denotes the distance from the slope crest to the observed subsidence crack in the roadway.

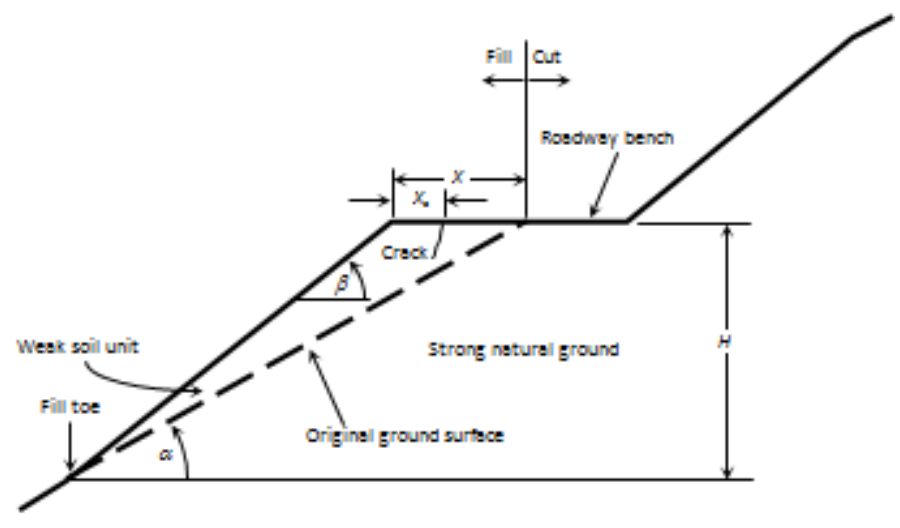

Figure 2: Typical cross-section of a side cast road embankment fill (after Musser and Denning (6)) and slope geometry

Figure 3 shows photographs of two roadways on steep hillsides in the States of Washington and Oregon for which subsidence is apparent by observed subsidence cracks in the asphalt concrete layer of the roadway. In these two examples, the distance $X_{c}$ is smaller for the first example as compared to the second. A survey (5) of 48 individual sites on 11 roads within four national forests in the States of Washington and Oregon was conducted to document the range of slope configuration parameters defined in Figure 2. Table 1 provides a summary of these parameters. Numerical models were created to have configurations that fall within the range of parameters listed in Table 1. 

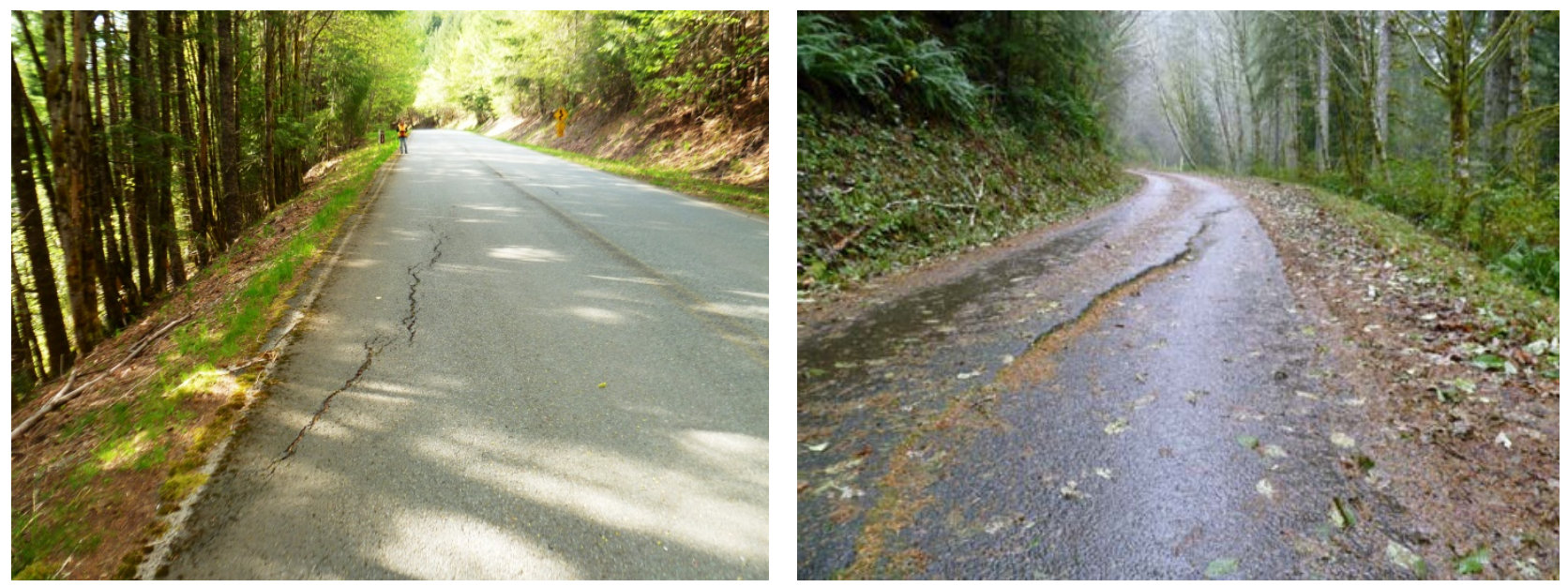

Figure 3: Examples of distress along roadways constructed by side cast methods

Table 1: Slope configuration parameters

\begin{tabular}{ccc}
\hline $\begin{array}{c}\text { Slope Geometry } \\
\text { Parameter }\end{array}$ & Range of Values & $\begin{array}{c}\text { Value used for 2D } \\
\text { models }\end{array}$ \\
\hline$\beta$ & $34^{\circ}$ and $39^{\circ}$ & $39^{\circ}$ \\
$\alpha$ & $20-38^{\circ}$ & $29.8^{\circ}$ \\
$H$ & $3.0-18.3 \mathrm{~m}$ & $10.7 \mathrm{~m}$ \\
$X$ & $0.9-9.1 \mathrm{~m}$ & $5.5 \mathrm{~m}$ \\
$X_{c}$ & $1.8-6.4 \mathrm{~m}$ & --- \\
\hline
\end{tabular}

Side cast fill slopes generally consist of a mixture of granular and fine grained soils and are rarely composed of purely cohesive soils. Limit equilibrium and finite difference models of unreinforced side cast fill slopes where the fill was modeled as a single uniform unit of soil and where failure surfaces were allowed to develop within the body of the unit, showed that large values of $X_{c}$ were observed only when the fill was assigned unrealistically high values of cohesion and low to zero values of friction angle. On the other hand, low to moderate values of $X_{c}$ were possible for values of cohesion and friction angle that fall within expected ranges for commonly encountered side cast fill materials. Since large values of $X_{c}$ were physically observed in the field for typical granular fill materials with fines, it was postulated that in these cases, failure occurred along the contact interface between the fill material and the original native ground. These observations led to the need to create two types of numerical models, which together result in predictions of values of $X_{c}$ that span the range observed in the field. These two types of models include one where the side cast fill soil is modeled as a single unit and one where a thin layer of weak soil is included along the contact interface between the fill soil and original ground. The failure surfaces resulting from these two types of models are referred to as rotational and wedge failures, respectively.

\section{DPERG NUMERICAL MODEL}


Two-dimensional finite difference numerical models were analyzed to study the effect of depth of the deep patch, layer spacing and required reinforcement tensile strength for long slopes where plane strain conditions can be assumed.

\section{Unreinforced Slope}

A model of an unreinforced slope was first developed and had the configuration parameters given in Table 1. The slope was analyzed for rotational and wedge failures. Table 2 lists the soil properties used in the two models.

Table 2: Slope soil properties for rotational and wedge failures

\begin{tabular}{ccccc}
\hline Failure Type & Soil Unit & $\phi\left(^{\circ}\right)$ & $c(\mathrm{kPa})$ & $\begin{array}{c}\gamma \\
\left(\mathrm{kN} / \mathrm{m}^{3}\right)\end{array}$ \\
\hline \multirow{2}{*}{ Rotational } & Weak & 23 & 5.3 & 19.7 \\
& Strong/Native & 50 & 0 & 19.7 \\
\hline \multirow{2}{*}{ Wedge } & Weak & 32 & 9.6 & 19.7 \\
& Slip Plane & 0 & 13.2 & 19.7 \\
& Strong/Native & 50 & 0 & 19.7 \\
\hline
\end{tabular}

Figure 4 shows the general configuration of the numerical model and illustrates results for the case of a rotational failure. For this model, the distance along the roadway bench containing the strong/native soil unit is $5.5 \mathrm{~m}$ and corresponds to the value of $X$. Only a portion of the roadway bench is shown in Figure 4 to better illustrate results within the weak soil unit where failure occurs. The weak soil unit having the properties listed in Table 2 is contained within the wedge of soil demarcated by the dashed black line inclined at the angle $\alpha$ (see Figure 2). The strong/native soil unit lies below and to the right of the weak soil unit. The results shown in Figure 4 are contours of shear strain rate at failure. Shear strain rate is calculated within the body of the slope at the point in the analysis where failure occurs. These results help locate the failure surface by following a path of largest values of shear strain rate. The point where this path initiates along the crest of the slope gives the distance $X_{c}$ defined in Figure 2, which in this case is $2.0 \mathrm{~m}$.

Figure 5 presents an alternative set of results from this analysis corresponding to velocity vectors plotted at the point of failure. The magnitude and direction of the vectors gives an indication of the relative movement of soil involved in the failure process. Also shown in Figure 5 as a solid black arc is a failure surface produced by the analysis of this slope using a limit equilibrium slope stability program (ReSSA, ADAMA Engineering). The two failure surfaces produced by the numerical model and by the limit equilibrium model are seen to differ slightly with the numerical model producing a larger value of $X_{c}$ and an exit surface higher up the slope face. The soil parameters given in Table 2 were chosen to produce a factor of safety of 1.0 for this slope when using the limit equilibrium model. The numerical model also produced a factor of safety of 1.0. 




Figure 4: Shear strain rate contour results for rotational failure



Figure 5: Velocity vector results from numerical model and slip surface from limit equilibrium model for rotational failure

The same slope depicted in Figure 4 was analyzed for a wedge failure by including a 0.3 $\mathrm{m}$ thick layer along the interface between the weak soil unit and the strong/native soil unit and having the strength properties listed in Table 2 for the slip plane soil unit. Failure was seen to be contained within the slip plane soil unit until near the top of the slope where it initiated as a tension crack along the slope crest. The classic equation for sliding along an inclined plane (Equation 1) was used to determine the cohesion, $c$, listed in Table 2 for this analysis, needed to produce a factor of safety of 1.0. The slope geometry parameters used in Equation 1 are defined in Figure 2. The numerical model produced a factor of safety of 0.93 . The lower value is due to the failure surface following a more critical path corresponding to the development of a tension crack at the top of the slope. The model for a wedge failure gave a larger value of $X_{c}(2.5 \mathrm{~m})$ as compared to the rotational failure $(2.0 \mathrm{~m})$.

$F S=\frac{2 c \sin \beta}{H \gamma \sin \alpha \sin (\beta-\alpha)}$

Equation 1

The above analyses demonstrate the reasonableness of results produced by the numerical model and illustrates how results from the model can be used to assess movement and whether 
this movement extends up onto the roadway bench, which in turn helps define the condition and performance of the roadway.

\section{Reinforced Slope}

The two unreinforced and failed slopes presented above with a factor of safety of 1.0 were analyzed with the numerical model for a range of depths for the reinforcement soil unit and for various reinforcement spacing. An example of a reinforced slope with a depth of the reinforced soil mass of $1.5 \mathrm{~m}$ and a reinforcement spacing of $0.3 \mathrm{~m}$ and configured to analyze a rotational failure is shown in Figure 6. The black lines within the reinforced mass represent the 5 layers of reinforcement. Figure 7 shows the same slope configured to analyze a wedge failure. The tensile strength of the reinforcement layers was set to a relatively high value $(58 \mathrm{kN} / \mathrm{m})$ to preclude the possibility of tensile failure in any layer. For each analysis performed, the mobilized tensile strength was checked to confirm that the tensile strength was not exceeded. The mobilized tensile strength was documented and is discussed below to provide information on the strength required for various reinforcement configurations. In addition, the embedment length of the reinforcement, as seen in Figures 6 and 7, was sufficiently large and together with relatively high interaction coefficients prevented reinforcement pullout from occurring.

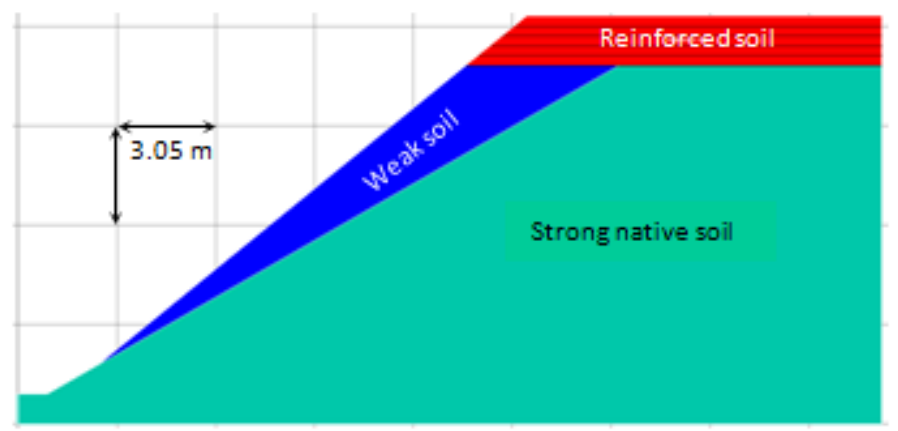

Figure 6: Reinforced slope configuration analyzed for a rotational failure with a reinforced depth of $1.5 \mathrm{~m}, 5$ layers of reinforcement and a layer spacing of $0.3 \mathrm{~m}$.

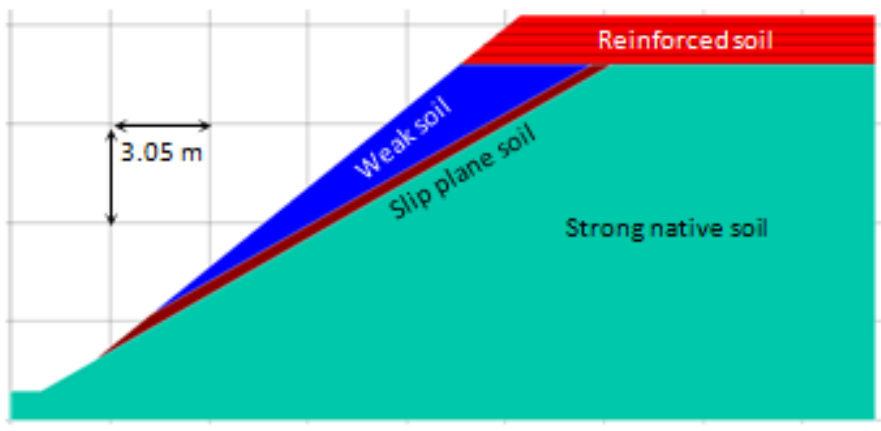

Figure 7: Reinforced slope configuration analyzed for a wedge failure with a reinforced depth of $1.5 \mathrm{~m}, 5$ layers of reinforcement and a layer spacing of $0.3 \mathrm{~m}$. 
Figures 8 and 9 show results of the slope displayed in Figure 6 in terms of shear strain rate contours and velocity vectors. This set of results, as compared to the unreinforced slope shown in Figures 4 and 5, shows that the reinforced mass prevents failure surfaces from initiating along the roadway bench and confines these surfaces to areas below the reinforced mass and along the slope face of the reinforced mass. This type of failure pattern matches the design goal associated with the DPERG technique.

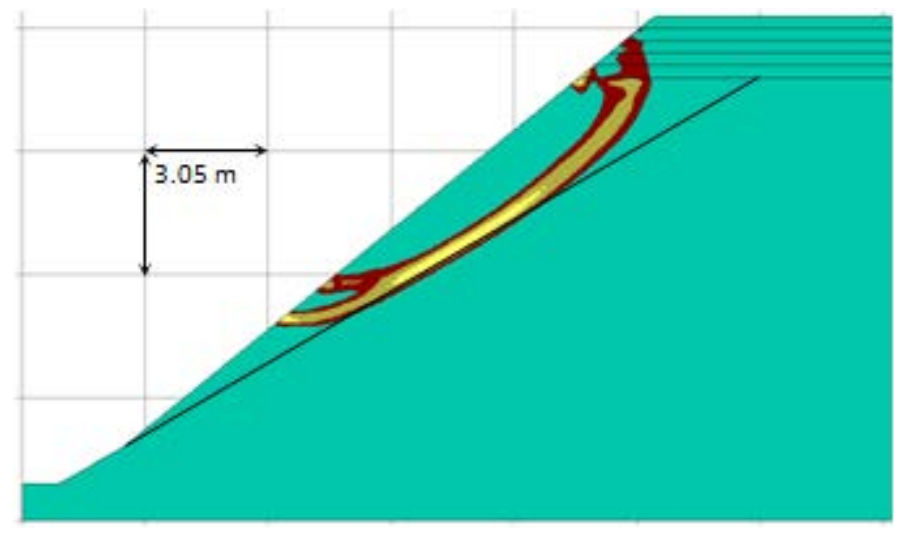

Figure 8: Shear strain rate contour results for a reinforced slope analyzed for a rotational failure with a reinforced depth of $1.5 \mathrm{~m}, 5$ layers of reinforcement and a layer spacing of $0.3 \mathrm{~m}$.

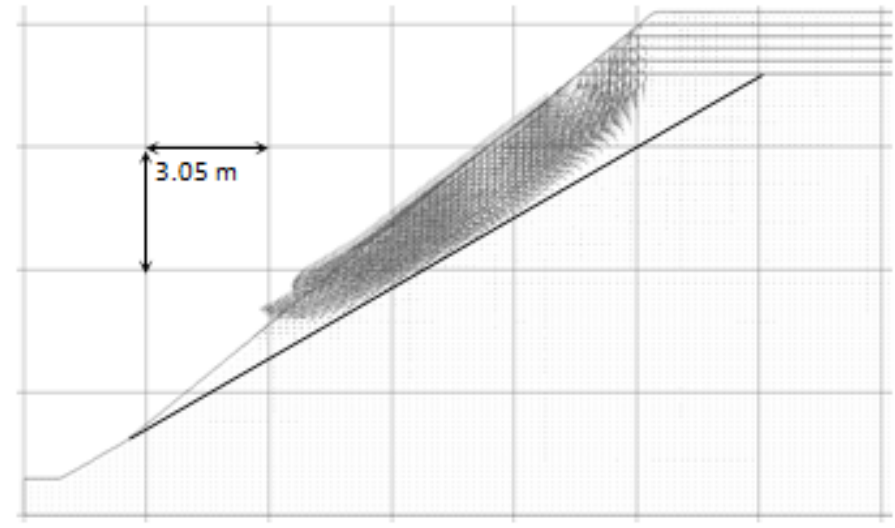

Figure 9: Velocity vector results for a reinforced slope analyzed for a rotational failure with a reinforced depth of $1.5 \mathrm{~m}, 5$ layers of reinforcement and a layer spacing of $0.3 \mathrm{~m}$.

Figures 10 and 11 show results for the slope analyzed for a wedge failure. These results also demonstrate that for this slope configuration and set of soil properties, the 5 layer reinforcement configuration with a spacing of $0.3 \mathrm{~m}$ satisfies the design philosophy of a DPERG by containing failure to a region that avoids the roadway bench. In general, rotational and wedge type failure models producing similar values of $X_{c}$ in the unreinforced model resulted in similar reinforcement requirements. Wedge type failures were necessary to produce models with the largest values of $X_{c}$. 


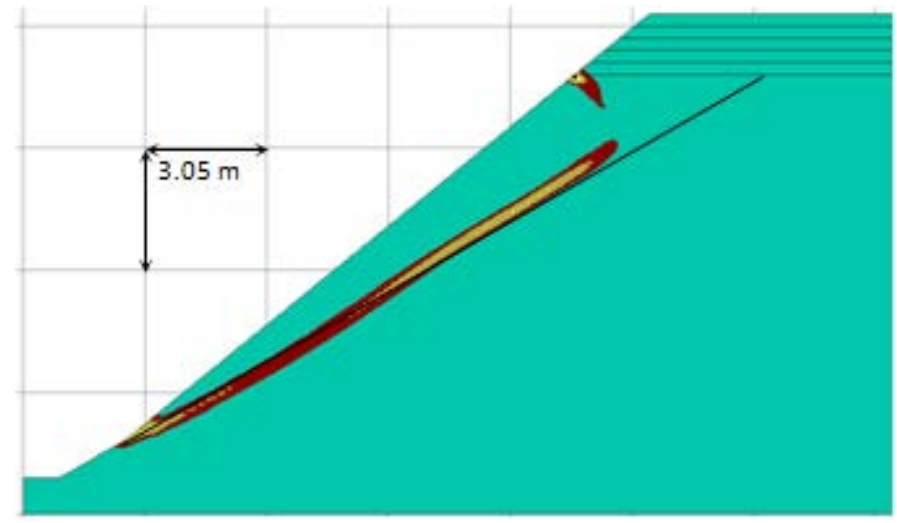

Figure 10: Shear strain rate contour results for a reinforced slope analyzed for a wedge failure with a reinforced depth of $1.5 \mathrm{~m}, 5$ layers of reinforcement and a layer spacing of $0.3 \mathrm{~m}$.

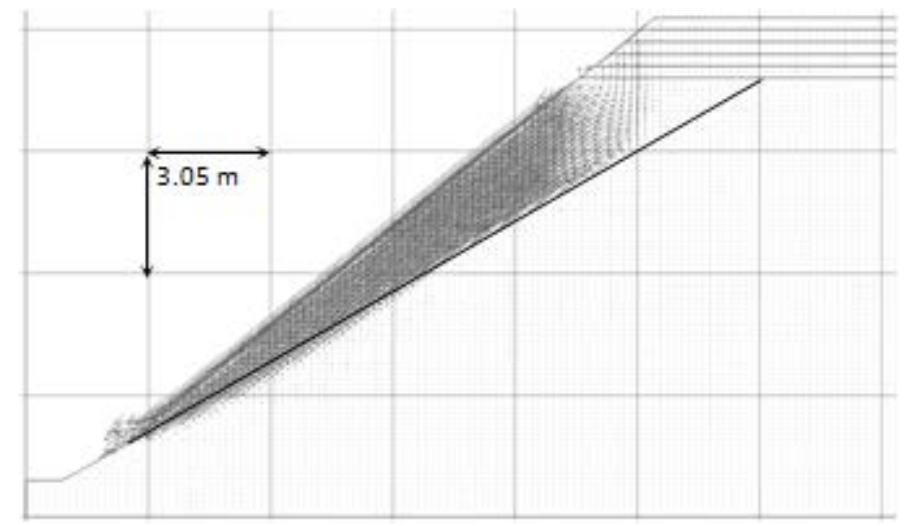

Figure 11: Velocity vector results for a reinforced slope analyzed for a wedge failure with a reinforced depth of $1.5 \mathrm{~m}, 5$ layers of reinforcement and a layer spacing of $0.3 \mathrm{~m}$.

The effect of depth of the reinforced mass and reinforcement spacing is shown in Figure 12 where velocity vector results are shown for 11 reinforcement configurations for the slope displayed in Figure 6, which corresponds to the analysis of rotational failures. In Figure 12, only the upper left portion of the slope is shown in order to better concentrate on movement within the reinforced mass along the roadway bench. The reinforcement configurations shown in Figure 12 range from 0.9 to $1.8 \mathrm{~m}$ for the depth of the reinforced mass and from 1 to 8 layers of reinforcement, giving a reinforcement spacing ranging from 0.15 to $1.2 \mathrm{~m}$. Figure 12 is organized by beginning with the shallowest depth of reinforced mass (i.e. $0.9 \mathrm{~m}$ ) and one layer of reinforcement. Performance is seen to be unacceptable from the standpoint of preventing failure surfaces and material movement from bisecting the roadway bench. As reinforcement layers are added, an improvement in performance is seen, however even for 6 layers of reinforcement at a spacing of $0.15 \mathrm{~m}$, performance is considered unsatisfactory. When the depth of the reinforced mass is increased to $1.2 \mathrm{~m}$, performance is seen to improve. For the case of 4 layers of reinforcement at a layer spacing of $0.3 \mathrm{~m}$ and for the case of 8 layers of reinforcement at a layer 
spacing of $0.15 \mathrm{~m}$, performance is considered to be marginally acceptable. The case with the least depth of reinforced mass and the least amount of reinforcement layers that appears acceptable from the viewpoint of the design philosophy of a deep patch is the case of $1.5 \mathrm{~m}$ of reinforced mass and 5 layers of reinforcement at a spacing of $0.3 \mathrm{~m}$. It is seen that the case of 1.8 $\mathrm{m}$ of reinforced mass and 3 layers of reinforcement at a layer spacing of $0.6 \mathrm{~m}$ is also acceptable and highlights the interplay between depth of the reinforced mass and layer spacing.

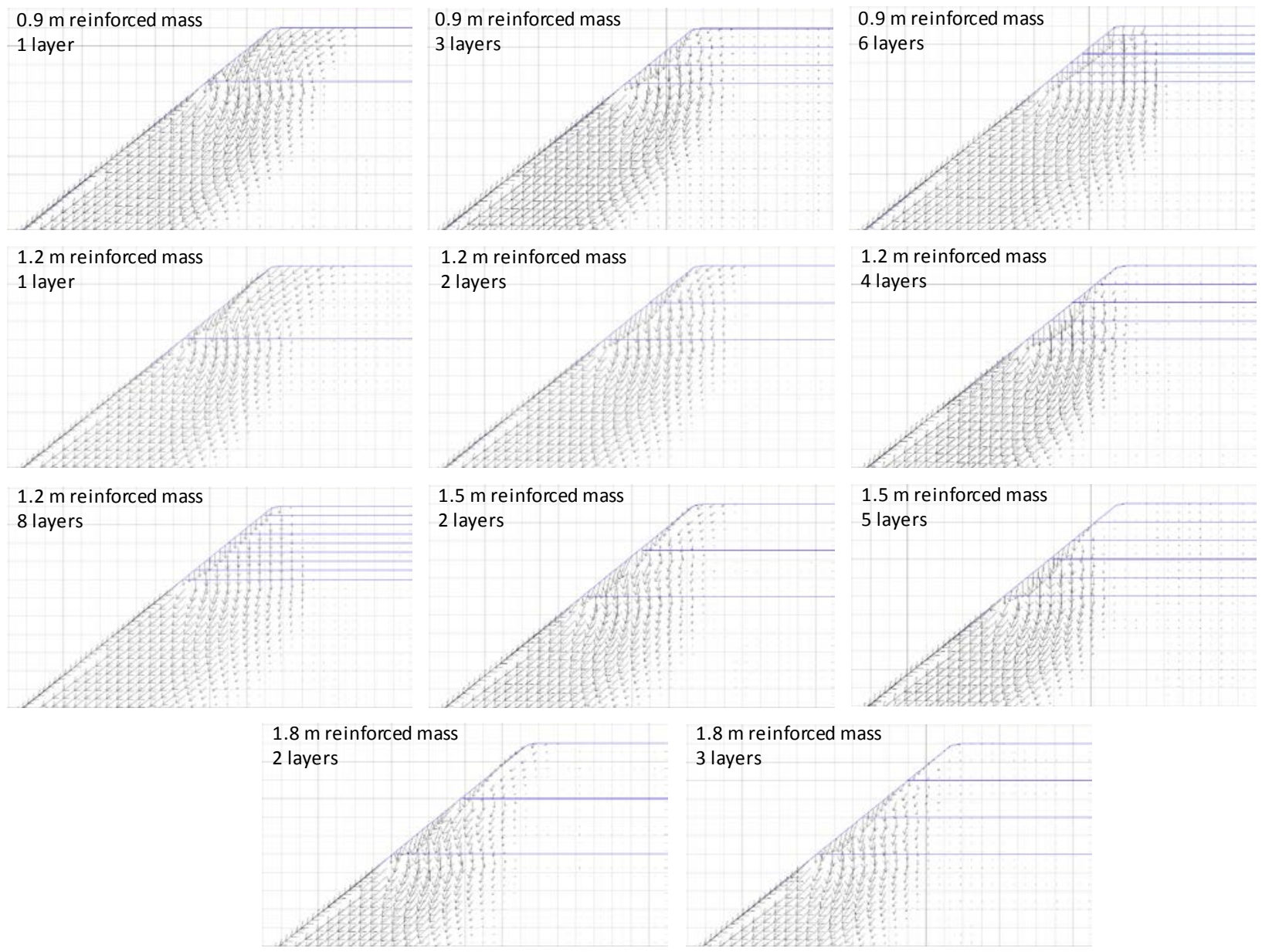

Figure 12: Velocity vector results for a range of reinforcement configurations for a slope analyzed for a rotational failure.

The examples presented above for assessing an optimal reinforcement configuration for a DPERG illustrates the subjective process used to assess acceptable versus unacceptable designs. The qualitative nature of viewing failure patterns to determine whether a repaired slope meets design goals differs from traditional methods of defining acceptable slope design by achieving a quantitative minimum factor of safety. The numerical model used produces a factor of safety based on the shear strength reduction technique, however this factor of safety is for a design chosen to produce a failure surface that does not intersect the roadway bench, According to the design philosophy of a deep patch, this factor of safety may be close to 1.0 while still achieving design goals. For example, the factor of safety produced by the numerical model for the slope 
shown in Figure 6 was 1.08, while this design resulted in a failure surface that did not intersect the roadway bench.

The limit equilibrium slope stability program referenced above was used to analyze this same slope where the slip circle initiation points were restricted to the horizontal surface of the roadway bench and produced a factor of safety of 1.25. This step is needed to ensure that failure surfaces extending up into the reinforced mass and initiating along the roadway bench have an adequate factor of safety associated with them. In this analysis, the reinforcement tensile strength was taken as an unfactored value equal to the average of the mobilized tensile strength values from the corresponding numerical model analysis, which equaled $10.5 \mathrm{kN} / \mathrm{m}$. Should an inadequate factor of safety exist, then the limit equilibrium analysis can be reanalyzed using a higher strength reinforcement. For this example, if a factor of safety of 1.3 was desired, the unfactored tensile strength of the reinforcement would need to be increased to $12.3 \mathrm{kN} / \mathrm{m}$.

This approach shows how several different reinforcement configurations can be acceptable. For instance, a less thick reinforced mass with tighter reinforcement spacing and a more thick reinforced mass with larger reinforcement spacing are both acceptable. In general, the results show that widely spaced reinforcement configurations do not allow for the reinforced mass to act as a composite and do not achieve the design goal of a deep patch.

\section{CONCLUSIONS}

This study illustrated the use of a numerical finite difference program for modeling and analysis of the DPERG technique. A two-dimensional commercial program was used to show the importance and interdependence of thickness of the deep patch reinforced mass and the reinforcement spacing. The numerical models showed patterns of material movement at the point of failure and showed that these patterns were dependent on the deep patch reinforcement configuration. Working from the premise that the goal of a DPERG design is to prevent failure surfaces from extending upwards onto the roadway bench, results from the numerical models, expressed in terms of patterns of material movement, produced optimal reinforcement configurations that met this goal. In general, this corresponds to relatively thin reinforcement spacing and a minimum depth of the reinforced mass that was dependent on slope geometry and soil strength parameters.

\section{ACKNOWLEDGEMENT}

The authors express their appreciation for the financial and technical support provided by the Western Federal Lands Division of the Federal Highway Administration.

\section{REFERENCES}

1. Powell, W., Keller, G.R., and Brunette, B. Applications for Geosynthetics on Forest Service Low-Volume Roads, In Transportation Research Record 1652, TRB, National Research Council, Washington, D.C., 1999, pp. 113-120.

2. Wu, J.T.H. and Helwany, S.M.B. Examining the Effects of Reinforcement in U.S. Forest Service Deep-Patch Landslide Repair Technique: Full-Scale Model Tests, In Transportation Research Record 1772, TRB, National Research Council, Washington, D.C., 2001, pp.203$210,2001$.

3. Ohta, H., Maeda, Y., Nishimoto, T., Ohmori, K., Yamakami, T., Iizuka, A., Kobayashi, I. and Hirata, M. A Series of Trial Embankments of Reinforced Earth, Proceedings of the $7^{\text {th }}$ International Conference on Geosynthetics, Nice, France, Vol. 1, pp. 307-312, 2002. 
4. Vulova, C. and Leshchinsky, D. Effects of Geosynthetic Reinforcement Spacing on the Performance of Mechanically Stabilized Earth Walls, Report No. FHWA-RD-03-048, FHWA, 2003.

5. Cuelho, E., Perkins, S. and Akin, M. Deep Patch Repair. Phase I: Analysis and Design, Report No. FHWA-WFL/TD-12-003, FHWA, 2012.

6. Musser, S.W. and Denning, C. Deep Patch Road Embankment Repair Application Guide, Report No. 0577 1204-SDTDC, USDA Forest Service and Federal Highway Administration, 2005. 